\begin{tabular}{|c|c|c|}
\hline & Int.J.Curr.Microbiol.App.Sci (2021) 10(12): 276-282 & \\
\hline & $\begin{array}{l}\text { International Journal of Current Microbiology and Applied Sciences } \\
\text { ISSN: 2319-7706 Volume } 10 \text { Number } 12 \text { (2021) } \\
\text { Journal homepage: } \underline{\text { http://www.ijcmas.com }}\end{array}$ & $\$$ \\
\hline $\begin{array}{l}\text { EXCELLENT } \\
\text { PUBLISHERS }\end{array}$ & & \\
\hline
\end{tabular}

\title{
Isolation of Causal Organism of Wilt and Collar Rot of Lentil and its Pathogenicity Tests
}

\author{
Abhishek Rathod ${ }^{1}$, Babli ${ }^{1}$, Shivangi Tiwari ${ }^{2}$, Dharmendra Mishra ${ }^{3}$, Ravi Patel $^{3}$, \\ Kamlesh Choubey ${ }^{3}$, Jyoti Kurmi ${ }^{2}$ and Dwarka* \\ ${ }^{I}$ Department of Plant Pathology, Rajmata Vijayaraje Scindhia Krishi Vishva Vidyalaya, \\ Gwalior, Madhya Pradesh, India \\ ${ }^{2}$ Eklavya University, Damoh, Madhya Pradesh, India \\ ${ }^{3}$ Swami Vivekanand University, Sagar, Madhya Pradesh, India \\ ${ }^{4}$ Department of Entomology, Jawahar Lal Nehru Krishi Vishwa Vidyalaya, Jabalpur, \\ Madhya Pradesh, India \\ *Corresponding author
}

\section{A B S T R A C T}

Keywords

Lentil,

chlamydospores,

growth,

discoloration and

infecting

\section{Article Info}

Received:

05 November 2021

Accepted:

30 November 2021

Available Online:

10 December 2021
The disease appears in the field in patches at both seedling and adult stages. Seedling wilt is characterized by sudden drooping, followed by drying of leaves and seedling death. The roots appear healthy, with reduced proliferation and nodulation and usually no internal discoloration of the vascular system. The fungus Fusarium oxysporum $\mathrm{f}$. sp. lentis is septate, profusely branched growth on potato sucrose / dextrose agar at $25^{\circ} \mathrm{C}$, initially white turning light buff or deep brown later and fluffy or submerged. The growth becomes felted or wrinkled in old cultures. Various types of pigmentation (yellow, brown, whitish /cream, crimson dark purple, light orange) may be observed in culture on solid medium. Microconidia were usually borne on simple and short conidiophores, which arise laterally on the hyphae. They are oval to cylindrical, straight or curved and measure $2.5-3.5 \times 5-11 \mu \mathrm{m}$. Macroconidia are borne on branched conidiophore, thin walled, 1 to 6 septate, fusoid, pointed at both ends and measures $3.5-4.5 \times 25-65 \mu \mathrm{m}$. Chlamydospores are formed in old cultures, which are smooth or rough walled, terminal intercalary and may be formed singly or in pairs or in chains. The pathogen causes a lesion localized at or about the collar between the stem and the root. The lesions develop around the stem eventually forming a "collar" region.

\section{Introduction}

Lentil production in India has always been important as it is one of the most important rabi crops in the country. Lentil (Lens culinaris Medik.) is an important pulse crop and the second major source of protein (25\%) after soybean in human and animal diet. Lentil 
is important source of energy (353 kcal), protein $(25 \%)$, carbohydrate $(63 \%)$, sugar $(2 \%)$, fat $(1 \%)$, vitamin and antioxidant compounds. It is mainly cultivated in Madhya Pradesh, Uttar Pradesh, Bihar, and West Bengal, which account for $85 \%$ of total production of India. Lentil is grown as a rabi crop or winter crop in India and sown from October to November. It can be grown on a wide range of soils from light loams to black cotton soils and can stand even less fertile moderately alkaline soils and rainfed conditions. The crop matures in 90 to 120 days. The total area under lentil in India was 12.76 lakh ha with a total production of 9.76 lakh ton and $765 \mathrm{Kg} / \mathrm{ha}$ productivity.

In Madhya Pradesh lentil was cultivated in an area about 5.5 lakh ha with production of 2.33 lakh tone and $424 \mathrm{~kg} / \mathrm{ha}$ productivity (Anonymous 2016-17) ${ }^{(1)}$. Lentil suffers from attack of a number soil born diseases such as vascular wilt (Fusarium oxysporum f.sp. lentis), collar rot (Sclerotium rolfsii), root rot (Rhizoctonia solani) etc. Productivity of lentil is reduced by the diseases by infecting to leaves, stems, roots and pods. It also reduces marketability due to discoloration of seeds (Khalequzzaman, 2016) $^{(3)}$. Fusarium wilt causes yield losses upto $50 \%$ in India. The disease appears in either early stage of crop growth (seedling) or during the reproductive stage (adult stage) (Khare 1981; Stoilova and Chavdarov, 2006) ${ }^{(4)(7)}$.

\section{Materials and Methods}

\section{Equipments and apparatus}

The equipments and apparatus which have been used in the study are given below:Laminar air flow, BOD incubator, Refrigerator, Autoclave, Glassware, Microscope, Hot air oven, Electronic balance, Forceps, Inoculation Needle, Cork borer, Blade etc.

\section{Cleaning and sterilization of equipments}

Corning make glassware were used during the period of investigation. All the glassware were cleaned with chronic acid, followed by thorough washing with detergent powder and then rinsing tap water before use.

The sterilization of media was done at $15 \mathrm{lbs}$, pressure for $20 \mathrm{~min}$. Petriplates were sterilized in hot air sterilizer at $180^{\circ} \mathrm{C}$ for $2 \mathrm{hrs}$. The plastic petriplates used in bio control study, were sterilized by alcohol. The isolation chamber was sterilized by alcohol, followed by ultraviolet exposure for $20 \mathrm{~min}$.

The other equipments used in isolation chamber like forceps, inoculation needle, cork borer, blade, etc. were sterilized by dipping them in alcohol, followed by heating on flame.

\section{Media}

\section{Potato Dextrose Agar (PDA) medium}

Peeled and sliced potato - $200 \mathrm{~g}$ Dextrose - 20 $\mathrm{g}$

Agar-agar - 20 g

Distilled water - $1000 \mathrm{ml}$

\section{Trichoderma-selective agar medium}

$\mathrm{MgSO}_{4} 7 \mathrm{H}_{2} \mathrm{O}-0.2 \mathrm{~g}$

$\mathrm{K}_{2} \mathrm{HPO}_{4}-0.9 \mathrm{~g}$

$\mathrm{KCl}-0.15 \mathrm{~g}$

$\mathrm{NH}_{4} \mathrm{NO}_{3}-1.0 \mathrm{~g}$

Glucose - $3.0 \mathrm{~g}$

Hloramphenicol - 0.25 g P-dimethylaminobenzenediazo sodium - $0.3 \mathrm{~g}$ Pentachloronitro- 
benzene $-0.2 \mathrm{~g}$ Rose-bengal - $0.15 \mathrm{~g}$

Agar - $20 \mathrm{~g}$

Distilled water - 1 lit.

Sterilization procedure Sterilization of glass wares

Glass wares were washed in liquid detergent under running tap water, and rinsed with distilled water 2-3 times. These were air-dried and then kept in oven for sterilization at $180^{\circ} \mathrm{C}$ for at least 2 hrs. Plastic wares were autoclaved at $121^{\circ} \mathrm{C}, 15 \mathrm{psi}$ for $15 \mathrm{~min}$.

\section{Sterilization of inoculating needles, forceps,} cork - borer and working table

Clean inoculating needle was sterilized by dipping the loop of needle in spirit and heating over the flame until red - hot. The process was repeated 2-3 times. Forceps and cork - borer were also sterilized in the way of needle. The working table of laminar air flow was disinfected by sweeping with cotton soaked in absolute alcohol and exposing it to UV light for 30 minutes.

\section{Sterilization of media and distilled water}

Sterilized glassware and plastic wares were used for dispensing media and distilled water. All media were autoclaved at $121^{\circ} \mathrm{C}, 15 \mathrm{psi}$ pressure for 15-30 min.

\section{Sterilization of laminar air flow}

Prior to the day of inoculation of fungus sample, the laminar air flow was saturated with alcohol vapors. At the time of inoculation the laminar air flow chamber was wiped with $70 \%$ alcohol or general spirit. Then only required instruments were kept in the chamber and exposed to UV rays for 15-20 min.

\section{Sterilization of media}

In all cases $100 \mathrm{ml}$ medium was poured in 150 $\mathrm{ml}$ Erlenmeyer flask, separately plugged with non-absorbent cotton and sterilized in an autoclave.

\section{Source of seeds and other materials}

Lentil seeds and fungicides, talc based formulation of Trichoderma strains were obtained from the Department of Plant Pathology R.A.K. College of Agriculture, Sehore (M.P.)

\section{Collection of diseased plant samples}

Wilt and Collar rot of lentil plants were collected from sick plot of R.A.K. College of Agriculture, Sehore (M.P.) at vegetative and flowering stages. Samples were brought in laboratory and symptoms were recorded in detail. The tissues of affected plants showing the symptoms of wilt and collar rot were observed under microscope for the presence of the causal agent.

\section{Isolation and purification of the pathogen}

Small pieces of infected tissues 1 to $2 \mathrm{~mm}$ dimension from the advancing margin of the spot, adjacent to healthy portions were cut with blade, washed well in distilled water to remove dust adhered to the infected pieces. Pieces were dipped in 1 per cent sodium hypo chloride solution for 30 seconds and finally washed well in three changes of sterilized distilled water.

The bits were then transferred to PDA petri plates or slants with the help of inoculating needle under aseptic condition and incubated at $28 \pm 1^{\circ} \mathrm{C}$. After $72 \mathrm{hrs}$, fragments of hyphal growth from the growing tips were transferred to fresh PDA petri plates or slants. Pure culture was made; following repeated hyphal 
tip transfer. Pure culture was maintained on PDA slants by sub culturing it at 30 days intervals. For preservation of cultures the plugged end of the culture tubes were dipped in melted wax and stored in a refrigerator at 5 \pm 1 .

\section{Pathogenicity tests Pot inoculation method}

The test fungus was multiplied on soil was sand maize medium for 7 days. Sterilized soil was used in pot experiment. The soil was collected from the local field and dried thoroughly sterilized. Pots of $25 \mathrm{~cm}$ face diameter were during experiments. The pots were filled with $1 \mathrm{~kg}$ sterilized soil and $20 \mathrm{~g}$ of inoculum was added in each pot. One inch of soil was placed over the inoculum. The contents were then mixed and surface sterilized seeds were sown and covered by half inch layer of soil. In control, no inoculum was added and pots were filled with sterilized soil. Ten seeds of variety RVL-31 were sown in each pot.

\section{Results and Discussion}

The collar rot and wilt pathogen was isolated from the diseased lentil plants. The infected tissues with healthy tissues were cut into small pieces of 0.5 to $1.0 \mathrm{~cm}$ long bits. The bits were surface sterilized by dipping in $1 \%$ sodium hypochlorite $(\mathrm{NaHCl})$ solution for $1 \mathrm{~min}$. The excess water on the surface of the pieces was removed by blotting on sterile blotting paper. The sterilized pieces were placed on potato dextrose agar medium supplemented with 200 ppm streptomycin. The plates were incubated at $28 \pm 1{ }^{\circ} \mathrm{C}$ and examined daily for the growth of mycelium of Sclerotium rolfsii. Hyphal tip transfer was made aseptically to potato dextrose agar (PDA) plates amended with 200 ppm streptomycin. The fungus grew upto 90 $\mathrm{mm}$ in 3 days on potato dextrose agar (PDA) medium. It produced extensive and white mycelium in culture medium. The mycelium was hyaline, much branched and hyphae thin walled, septate, connection and sclerotia were small, mustard shape, white round bodies with clamp in the beginning, later becoming light to dark brown with shine and measuring 1.0 to $1.15 \mathrm{~mm}$ in size of Sclerotium rolfsii (Plate-1) and The mycelium was oval to cylindrical, straight or curved and measure $2.5-3.5$ x 5 $11 \mu \mathrm{m}$. Macroconidia are borne on branched conidiophore, thin walled, 1 to 6 septate, fusoid, pointed at both ends and measures 3.5 - 4.5 x 25 - $65 \mu \mathrm{m}$. Chlamydospores are formed in old cultures, which are smooth or rough walled, terminal intercalary and may be formed singly or in pairs or in chains of Fusarium oxysporum f. sp. lentis.

Antifungal activity of Trichoderma spp. against Sclerotium rolfsii and Fusarium oxysporum f. sp. lentis.

The result of interaction between Trichoderma strains mycelia and Sclerotium rolfsii and Fusarium oxysporum f. sp. lentis mycelia in dual culture indicated that there is a statistical difference in the overall growth. More than 60 $\mathrm{mm}$ diameter was observed in $T$. viride, $T$. harzianum-5, T. harzianum-4, T. harzianum-1. The mycelial growth of $T$. harzianum-5 and Sclerotium rolfsii in dual culture were 66.2 $\mathrm{mm}$ and $24.2 \mathrm{~mm}$ followed by $T$. viride $65.1 \mathrm{~mm}$ and $26.3 \mathrm{~mm}$ and the mycelial growth of $T$. viride and Fusarium oxysporum f. sp. lentis in dual culture were $75.3 \mathrm{~mm}$ and 15.7 $\mathrm{mm}$ followed by $T$. harzianum-5 $70.1 \mathrm{~mm}$ and $20.6 \mathrm{~mm}$ respectively after $168 \mathrm{hrs}$ of incubation.

The findings of the investigation entitled Studies on Biological and Chemical Control of wilt and Collar rot of lentil caused by Fusarium oxysporum f. sp. lentis and Sclerotium rolfsii has been described and explained with support of relevant research work published by earlier workers on the subject as follow. 
Table.1 Antifungal activity of Trichoderma strains on radial growth of Sclerotium rolfsii after seven days of incubation.

\begin{tabular}{|c|c|c|c|}
\hline Treatment & $\begin{array}{c}\text { Colony diameter } \\
\text { of Sclerotium rolfsii } \\
(\mathbf{m m}) *\end{array}$ & $\begin{array}{c}\text { Colony diameter } \\
\text { of antagonist }(\mathbf{m m}) *\end{array}$ & $\begin{array}{c}\text { Inhibition growth of } \\
\text { Sclerotium rolfsii }\end{array}$ \\
\hline T. harzianum-1 & 30.5 & 60.2 & $\mathbf{5 1 . 2}$ \\
\hline . harzianum-2 & 34.4 & 56.4 & $\mathbf{4 9 . 2}$ \\
\hline T. harzianum-4 & 25.6 & 65.1 & $\mathbf{5 3 . 8}$ \\
\hline T. harzianum-5 & 24.2. & 66.2 & $\mathbf{5 5 . 1}$ \\
\hline T. viride & 26.3 & 64.3 & $\mathbf{5 7 . 6}$ \\
\hline T. mutant & 46.1 & 44.4 & $\mathbf{3 9 . 9}$ \\
\hline SE(m) & 0.79 & 1.33 & - \\
\hline C.D at 5\% & $\mathbf{2 . 4}$ & $\mathbf{4 . 1 0}$ & - \\
\hline
\end{tabular}

Table.2 Antifungal activity of Trichoderma strains on radial growth of Fusarium oxysporum f. sp. lentis after seven days of incubation.

\begin{tabular}{|c|c|c|c|}
\hline Treatment & $\begin{array}{c}\text { Colony diameter } \\
\text { Fusarium Oxysporum } \\
\text { f.sp. lentis }(\mathbf{m m}) * *\end{array}$ & $\begin{array}{c}\text { Colony diameter of } \\
\text { antagonist }(\mathbf{m m}) *\end{array}$ & $\begin{array}{c}\text { Inhibition growth of } \\
\text { Fusarium } \text { Oxysporum } \\
\text { f.sp. lentis }\end{array}$ \\
\hline $\boldsymbol{T}$. harzianum-1 & 23.2 & 67.2 & $\mathbf{5 8 . 9}$ \\
\hline $\boldsymbol{T}$. harzianum-2 & 33.4 & 57.5 & $\mathbf{5 0 . 2}$ \\
\hline $\boldsymbol{T}$ harzianum-4 & 28.5 & 62.4 & $\mathbf{5 7 . 2}$ \\
\hline $\boldsymbol{T}$. harzianum-5 & 20.6 & 70.1 & $\mathbf{6 1 . 2}$ \\
\hline T. viride & 15.7 & 75.3 & $\mathbf{6 5 . 9}$ \\
\hline T. mutant & 33.5 & 57.4 & $\mathbf{4 9 . 8}$ \\
\hline SE(m) & 0.83 & 1.67 & - \\
\hline C.D at 5\% & $\mathbf{2 . 5 6}$ & $\mathbf{5 . 1 6}$ & - \\
\hline
\end{tabular}

*Average of 3 replications.

Fig.1 Colony diameter of Trichoderma strains and Sclerotium rolfsii after seven days of incubation

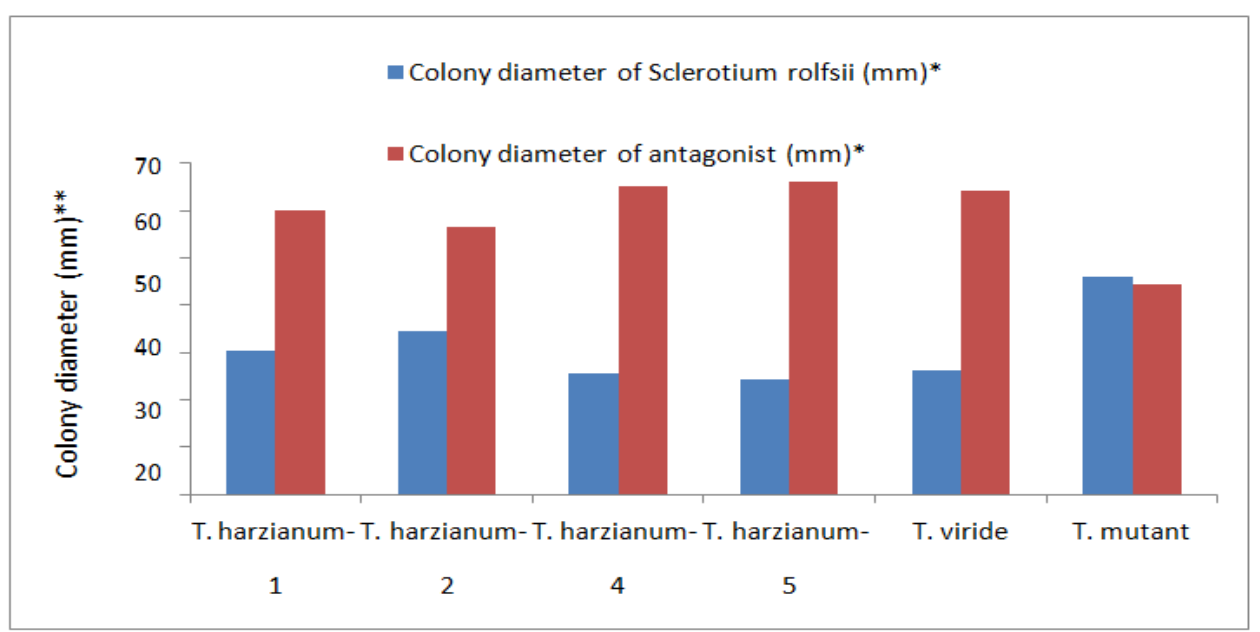


Fig.2 Colony diameter of Trichoderma strains and Fusarium oxysporum f.sp. lentis after seven days of incubation

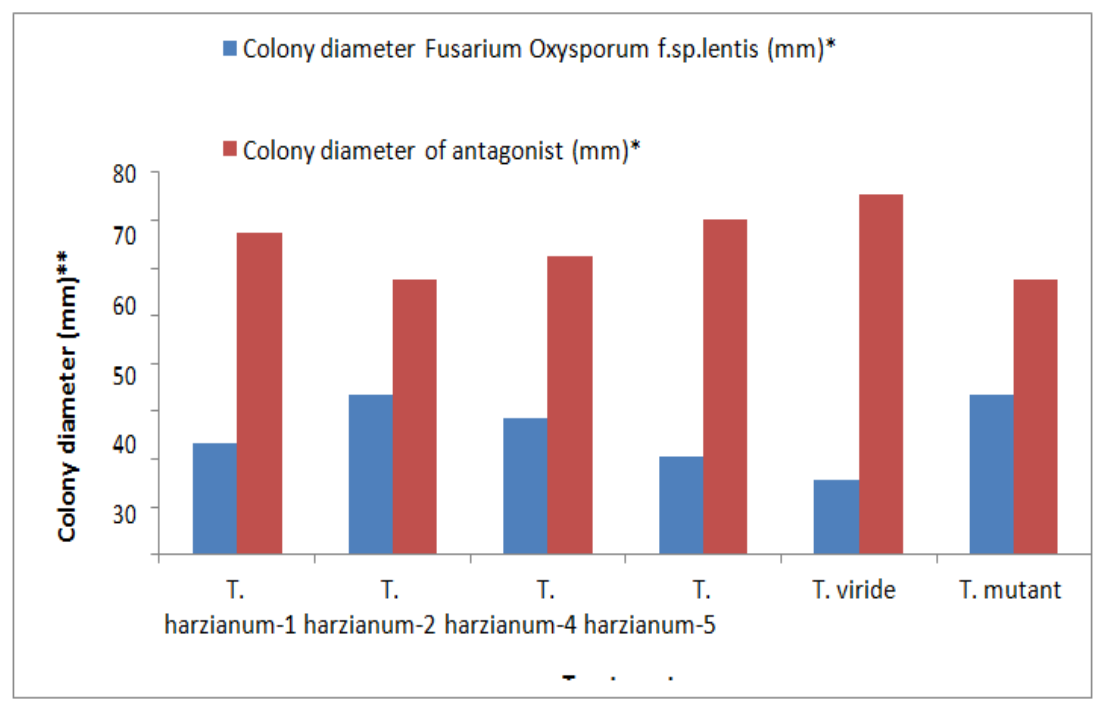

The wilt disease appeared in the field in patches at both seedling and adult stages. Seedling wilt is characterized by sudden drooping, followed by drying of leaves and seedling death. The roots appeared healthy, with reduced proliferation and nodulation and usually no internal discoloration of the vascular system. Adult wilt symptoms appear from flowering to late pod- filling stage and are characterized by sudden drooping of top leaflets of the affected plant, leaflet closure without premature shedding, dull green foliage followed by wilting of the whole plant or of individual branches. Haji et al., (2015) ${ }^{(2)}$ also described such wilt symptoms in lentil.

Pathogenicity of isolated fungi $F$. oxysporum f. sp. lentis was confirmed on lentil wilt susceptible variety L 9-12 by root dip and soil inoculation methods. Wilt symptoms were appeared after 15 days of inoculation in both the cases and Koch's postulates were confirmed by obtaining similar pathogen. Both these techniques were also demonstrated by Mohammadi et al., (2011) ${ }^{(6)}$. Isolation Sclerotium rolfsii fungi from infected lentil plant. The mycelium of the fungal culture on
PDA medium was white and fluffy. Small white tufts were formed on mycelium which later turned to dark brown, round, sclerotia and measured 1-2 $\mathrm{mm}$ in diameter. On inoculation of $S$. rolfsii the lentil plants exhibited seedling mortality after ten days and cottony white growth of the fungal mycelium was found around the collar region on which several mustard like sclerotia were observed, confirming the $S$. rolfsii. Xie et al., $(2014)^{(8)}$ also adopted. Similar methodology to prove pathogenicity of $S$. rolfsii in tomato plants. In this present investigation germination percentage in lentil seed treated with Trichoderma strains was significantly higher than control.

The germination percent ranged between 56.5 to 74.5 percent. Maximum germination was recorded in $T$. viride (74.5\%) followed by $T$. harzianum-5 $(72.5 \%)$ and T. harzianum$1(71.5 \%)$. Which was significantly superior to rest of treatments including control. Kumar et al., $\quad(2014)^{(5)}$ reported enhanced seed germination and vigor of chickpea by the seed treatment of Trichoderma strains. Trichoderma strains for bio-efficacy, 
compatibility with fungicides and growth promoting ability (GPA) of lentil, it could be concluded that Trichoderma strains viz. $T$. virie and $T$. harzianum-5. Among the Trichoderma strains $T$ harzianum-5 and $T$. harzianum-4 were highly compatible with hexaconazol+zineb, while strains $T$. harzianum-2, T. harzianum-4 were compatible with carboxin +thiram. Trichoderma strains $T$. viride increased growth of lentil plant followed by other Trichoderma strains viz. T.harzianum-5, T.harzianum-4, T. harzianum2 and T.mutant.

\section{References}

1. Anonymous. 2016-17. Project Coordinator MULLARF. ICAR, Kanpur.

2. Haji J, Feleke K, Endayen A and Cabi. 2015. Vascular wilt of lentil (Fusarium oxysporum f.sp. lentis) plantwise knowledge bank (Plantwise Technical Factsheet).

3. Khalequzzaman K M. 2016. Control of foot and root rot of lentil by using different management tools. $A B C \quad J$. of Advanced Research. 5 (1): 2312-203.
4. Khare M N. 1981. In: Diseases of Lentils, Eds: C Webb and G. Hawtin. Farnham Royal. UK: 1 C ARDA / CAB. pp. 163 -172 .

5. Kumar V, Mohammad S, Srivastava M, Singh A, Pandey S and Sharm A. 2014. Enhancing seed germination and vigor of chickpea by using potential and effective strains of Trichoderma Species. Virol and Mycol, 3: 2

6. Mohammadi N, Goltapeh E M, BabaieAhari and Puralibaba H. 2011. Pathogenic and genetic characterization of Iranian isolates of Fusarium oxysporum f. sp. lentis by ISSR analysis. J. of Agri. Technology Vol. 7 (1) : 63-72.

7. Stoilova T and Chavdarov P. 2006. Evaluation of lentil germplasm for disease resistance to fusarium wilt (Fusarium oxysporum f. sp. lentis). J.Central European Agri. 7: 121 - 126.

8. Xie C, Huang C H and Vallad E G. 2014. Mycelial Compatibility and Pathogenic Diversity Among Sclerotium rolfsii isolates in the Southern United States. Plant Disease:, 98(12): 1685-1694.

\section{How to cite this article:}

Abhishek Rathod, Babli, Shivangi Tiwari, Dharmendra Mishra, Ravi Patel, Kamlesh Choubey, Jyoti Kurmi and Dwarka. 2021. Isolation of Causal Organism of Wilt and Collar Rot of Lentil and its Pathogenicity Tests. Int.J.Curr.Microbiol.App.Sci. 10(12): 276-282. doi: https://doi.org/10.20546/ijcmas.2021.1012.032 